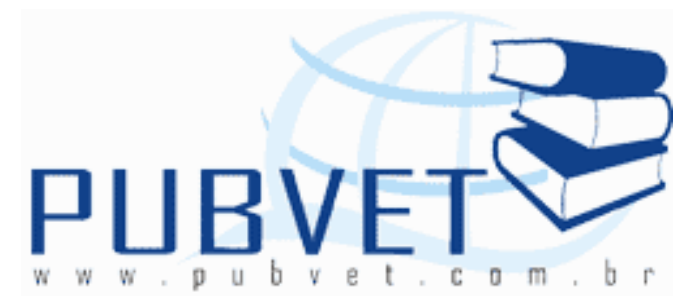

PUBVET, Publicações em Medicina Veterinária e Zootecnia.

\title{
Inseminação artificial em caprinos: Associação das biotécnicas de diluição e refrigeração do sêmen
}

Sabrina Missae Sakashita ${ }^{1}$, Carlos Frederico de Carvalho Rodrigues ${ }^{2}$, Leandro Rodello $^{1}$, Cláudia Dias Monteiro ${ }^{1}$, João Elzeário Castelo Branco Iapichini ${ }^{2}$

1-Pós graduandos da Faculdade de Medicina Veterinária e Zootecnia, UNESP Universidade Estadual Paulista, Departamento de Reprodução Animal e Radiologia Veterinária, Botucatu, SP, Brasil.

2 - Pesquisadores Científicos da APTA/SAA-SP

\section{Resumo}

Das diversas biotecnologias disponíveis para a intensificação do manejo reprodutivo, preconiza-se a programação reprodutiva e distribuição dos cios e partos ao longo do ano, alicerçadas pelo uso racional da Inseminação Artificial. Essa biotécnica, com sêmen refrigerado em caprinos, apresenta resultados práticos mais viáveis, tanto do ponto de vista econômico quanto produtivo, com índices reprodutivos mais próximos daquele obtido em monta natural ou sêmen fresco, e superiores daqueles obtidos com sêmen congelado. É característico do sêmen caprino a síntese e secreção de enzimas pelas glândulas bulbo uretrais, liberadas no plasma seminal. Em função dos efeitos deletérios, a composição enzimática do sêmen do bode e os diluidores assumem grande importância no processo de conservação do sêmen congelado ou refrigerado. Aliada a outras biotécnicas reprodutivas, a inseminação 
artificial representa importante opção como agente de otimização de diferentes sistemas de produção de caprinos, contribuindo para uma melhor distribuição dos partos ao longo do ano, diminuindo ou até mesmo suprimindo a entressafra de leite, carne e animais reprodutores, abrandando entraves econômicos e estratégicos para o setor. O uso de qualquer técnica de manejo deverá avaliar o seu impacto sobre a produção animal do ponto de vista biológico e financeiro. Desta forma, contínuas investigações científicas e esperadas inovações biotecnológicas e sociais para o agronegócio caprinocultura são importantes instrumentos de desenvolvimento regional sustentável.

\title{
Artificial insemination in goats: Biotechnology association of dilution and cooling of semen
}

\begin{abstract}
Of the several available biotechnologies for the enhancement of reproductive management, it is recommended programming and distribution of reproductive cycles and deliveries throughout the year, underpinned by rational use of Artificial Insemination. This biotech, with cooled semen in goats, practical results more viable, both economically and productive, with reproductive rates closer to that obtained by natural service or fresh semen, and superior to those obtained with frozen semen. It is characteristic of goat semen synthesis and secretion of enzymes by the bulbourethral glands, released into the seminal plasma. In light of the deleterious effects, the enzymatic composition of goat semen and extenders are of great importance in the preservation of semen frozen or refrigerated. Combined with other reproductive biotechnologies, artificial insemination is an important option as agent optimization of different systems of goat production, contributing to a better distribution of births throughout the year, reducing or even eliminating the off season milk, meat and breeding animals, slowing down economic barriers and strategy for the sector. The use of any management technique should assess their impact on
\end{abstract}


animal production in terms of biological and financial information. Thus, continuous scientific research and biotechnological innovations expected to agribusiness and social goats are important instruments for sustainable regional development.

\section{Introdução}

Como agronegócio, a caprinocultura apresenta acentuado crescimento nos últimos anos no Brasil, particularmente no Estado de São Paulo e Paraná, seja pelo aumento no efetivo dos rebanhos, seja pelo aumento no número de propriedades envolvidas nessa atividade e suas especializações, verificando-se ainda expressivo crescimento da demanda de carne, pele, e notadamente, matrizes e reprodutores com elevado valor de comercialização.

Das diversas biotecnologias disponíveis para a intensificação do manejo reprodutivo, preconiza-se a programação reprodutiva e distribuição dos cios e partos ao longo do ano, alicerçadas pelo uso racional da Inseminação Artificial (IA).

A IA possibilita a utilização de indivíduos geneticamente superiores com menores custos por serviço. Além disso, elimina a necessidade de transporte dos animais, os custos e inconvenientes da manutenção de um grande número de machos reprodutores na propriedade, possibilitando ainda a realização de programas de melhoramento genético, de cruzamentos industriais e controle de determinadas enfermidades.

A IA com sêmen refrigerado em caprinos apresenta resultados práticos mais viáveis, tanto do ponto de vista econômico quanto produtivo, com índices reprodutivos mais próximos daquele obtido em monta natural ou sêmen fresco, e superiores daqueles obtidos com sêmen congelado.

Entretanto, o êxito desta biotecnologia depende em grande parte do desenvolvimento e emprego de diluentes satisfatórios, cujo emprego visa aumentar o volume do ejaculado, proteger os espermatozóides durante o 
resfriamento prolongando sua sobrevivência, além de apresentar efeitos benéficos sobre a fertilidade.

\section{Características e biotécnicas de conservação do Sêmen caprino}

O sêmen caprino apresenta particularidades que o diferencia do sêmen de outras espécies. A mais importante é característico do sêmen caprino a síntese e secreção de enzimas pelas glândulas bulbo uretrais, liberadas no plasma seminal (SIMPLÍCIO \& MACHADO, 1989).

O plasma seminal dos caprinos é rico em fosfolipase $A$, que ao interagir com os fosfolipídios da maioria dos diluidores, catalisa a hidrólise de lecitina presente na gema de ovo e liberam ácidos graxos e lisolecitinas, responsáveis pela ação detergente sobre os lipídios da membrana plasmática que são altamente tóxicos para os espermatozóides (ROY, 1957, IRITANI \& NISHIKAWA, 1961; AMMDAL et al., 1965, CORTEEL, 1974). A reação de hidrólise promove uma atividade fusogênica na membrana dos espermatozóides, induzindo a reação acrossômica e a descondensação da cromatina (ROY, 1957; GIBBONS, 2002; apud CASTELO et al., 2008).

Em função dos efeitos deletérios, a composição enzimática do sêmen do bode e os diluidores assumem grande importância no processo de conservação do sêmen congelado ou refrigerado (SIMPLÍCIO \& MACHADO, 1989).

No congelamento quando se utiliza sêmen caprino total, ocorre à redução do número de espermatozóides vivos sendo diretamente proporcional ao tempo de armazenamento e a remoção do plasma seminal pela centrifugação imediatamente após a coleta do sêmen, antes do congelamento, mostrou ser benéfica à sobrevivência das células espermáticas pós-descongelação em vários trabalhos (CORTEEL 1974; RITAR \& SALAMON, 1982; TULI \& HOLTZ, 1994; MACHADO \& SIMPLÍCIO, 1995; LEBOUEF, 2000).

Para Corteel (1977); Ritar e Salamon (1982); Tuli e Holtz (1994); na espécie caprina, quando ocorreu a remoção do plasma seminal no processo de 
centrifugação, contribuindo na percentagem de células vivas e motilidade durante o congelamento, em diluentes de gema de ovo ou leite.

Dunner et al., (1993) observaram que amostras de sêmen total e com remoção do plasma seminal, quando apenas refrigeradas, não apresentaram diferenças significativas quanto à motilidade espermática progressiva. Porém, Salvador et al., (2006), obtiveram melhor viabilidade do sêmen refrigerado por longa duração, quando utilizaram meio a base de leite e remoção de plasma seminal. Roca et al., (1997), não obtiveram nenhuma melhora na remoção do plasma seminal na viabilidade in vitro ou na fertilidade in vivo em sêmen diluído em TRIS, submetido à refrigeração.

Ritar e Salamon (1982) recomendaram o uso de 1,5\% de gema de ovo, sem remoção do plasma seminal, como uma alternativa prática em sêmen congelado.

Nunes (1982), citado por LEBOEUF et al., (2000), acrescentou que os produtos oriundos das glândulas bulbo-uretrais possuem componentes importantes na preservação dos espermatozóides de bode.

Outros autores, (BISPO, 2005; VIANA et al., 2006; PALOMINO et al., 2007), quando avaliaram a eficácia da diluição em glicose-leite e Tris-gema de ovo, sem centrifugação do plasma seminal submetido à refrigeração observaram que a presença do plasma seminal não influenciou as características do sêmen pós-refrigeração.

Porém Azerêdo et al., (2001), utilizando o diluente com 2,6\% de gema de ovo, concluíram que a remoção de plasma seminal foi prejudicial ao sêmen fresco e ao submetido à congelação, uma vez que o percentual de espermatozóides com membranas plasmáticas integra e com motilidade espermática diminuíram após a centrifugação do plasma seminal.

\section{Meios diluidores para sêmen de caprinos}

Os diluidores além de aumentarem o volume seminal, permitindo seu fracionamento, exercem papel fundamental na preservação do sêmen, 
tanto no processo de refrigeração quanto no de congelação (SALAMON \& MAXWELL, 2000).

É muito importante a escolha de um bom diluente, onde este deve ser atóxico para os espermatozóides, ser de baixo custo, preparo fácil e ter pH e pressão osmótica compatíveis com a sobrevivência espermática, inibir o crescimento bacteriano sendo fundamental na conservação, pois deverá conter substâncias que ao mesmo tempo proporcionem aporte nutricional e proteção às células contra o choque térmico que ocorrem durante as curvas de refrigeração.

Os diluidores para conservação espermática devem possuir uma substância orgânica que atue como crioprotetor externo, como a gema de ovo ou leite desnatado já que a fosfatidilcolina (lecitina) e as lipoproteínas da gema e a caseína do leite protegem os espermatozóides durante a refrigeração, contra o choque térmico que se produz ao refrigerar o sêmen desde os $20^{\circ} \mathrm{C}$ aos $5^{\circ} \mathrm{C}$ (MIES FILHO et al., 1982; DAS \& RAJKONWAR, 1995); uma fonte de energia, como a glicose ou frutose; um componente tampão, como citrato de sódio ou hidroximetil aminometano (TRIS); um crioprotetor interno que proteja os espermatozóides durante o congelamento, a exemplo do glicerol, dimetilsulfóxido (DMSO), etilenoglicol; e antibióticos para prevenir o crescimento bacteriano, como penicilina, estreptomicina ou gentamicina (EVANS \& MAXWELL, 1987).

Um relevante número de diluidores de sêmen caprino tem sido utilizado em testes de laboratórios e de fertilidade, tais como: salina, citrato de sódio-gema (Citrato-Gema), citrato de sódio-frutose-gema, sacarose-EDTA, bicarbonato de cálcio-gema, Tris-gema (LEBOEUF et al., 2000), água de coco (SIMPLICIO, 1987), leite em pó ou reconstituído, com ou sem gema de ovo.

E os mais utilizados para a conservação do sêmen na forma líquida $\left(4^{\circ} \mathrm{C}-5^{\circ} \mathrm{C}\right)$ são: o leite em pó, os diluidores a base de citrato de sódio, Tris (LEBOUEF et al., 2000), gema de ovo (HERRERA e TAPIA, 1998; BISPO, 2005; VIANA et al., 2006; PALOMINO et al., 2007). 


\subsection{Leite desnatado}

O leite desnatado é a base mais utilizada nos diluidores de sêmen caprino para uso na inseminação artificial. A capacidade de fertilização dos espermatozóides estocados em diluente de leite ou à base de leite é de aproximadamente 12 a 24 horas. O leite é um meio fisiológico, porém complexo, por isso este componente apresenta-se com muitas variações nos resultados obtidos, e seus mecanismos de ação para preservação celular não estão bem elucidados (BISPO, 2005; LEBOEUF et al., 2003).

No caso dos diluidores à base de leite, uma fração protéica, também oriunda da glândula bulbo uretral, denominada BUSgp60, hidrolisa os seus triglicerídeos, resultando na produção de ácidos graxos tóxicos aos espermatozóides de caprinos, como o ácido oléico, capazes de inibir sua motilidade (CORTEEL et al., 1984; LEBOEUF et al., 2000).

O efeito BUSgp60 pode ser direto sobre os fosfolipídeos da membrana dos espermatozóides ou indireto, pela produção de derivados tóxicos dos lipídeos do leite (CORTEEL et al., 1984; LEBOEUF et al., 2000).

Alguns autores como Shamsuddin et al., (2000) relataram que o sêmen caprino sem lavagem, diluído em leite desnatado é viável por apenas 48 horas, porém, Salvador et al., (2007), relataram que na refrigeração a $5^{\circ} \mathrm{C}$ e o uso de diluidores a base de leite é um método viável para prolongar a viabilidade.

\subsection{Gema de ovo}

A uniformidade na preparação dos diluidores de sêmen contendo gema de ovo é difícil de ser atingida devido às suas características individuais, como idade do ovo, tipo de alimentação das aves, à variação na composição da gema de ovo, dependendo da linhagem da ave e a variação sazonal na concentração da enzima coaguladora da gema de ovo no plasma seminal (CORTEEL, 1973, ROCA et al., 1997).

Deve ser considerado, exclusivo do macho caprino, o fato das suas glândulas bulbo-uretrais produzirem, particularmente, uma fosfolipase (EYCE) 
que hidrolisa a lecitina da gema de ovo, formando ácidos graxos e lisolecitinas, esta última atuando sobre a membrana espermática danificando-a (ROY, 1957).

Essa lisolecitinas é tóxica devido a sua ação detergente sobre os lipídios da membrana plasmática (NUNES, 1982).

A gema de ovo atua na superfície da membrana plasmática, restaurando a perda de fosfolipídeos e, aparentemente, induzindo alteração transitória de sua composição, prevenindo a ruptura da membrana plasmática (FARSTARD, 1996). Os fosfolipídeos que compõe a fração LDL da gema de ovo protegem o sêmen, especificamente durante o processo de refrigeração a $5^{\circ} \mathrm{C}$.

As concentrações de gema de ovo rotineiramente utilizadas nos diluidores têm variado de 1,5\% a 50\% (WATSON, 2000; SALAMON \& MAXWELL, 2000) e sua redução é de grande interesse, uma vez que a combinação de gema de ovo e glicerol poderia promover uma estabilização ou desestabilização das membranas dependendo da concentração e do tempo de exposição dos espermatozóides frente a estes dois componentes (KATKOV et al., 1998), podendo gerar como conseqüência, uma maior produção de ROS (MORANI, 2004).

Segundo Rodello et al. (2011), a utilização de Glicina-Gema-Leite 5\% (GGL5\%) em sêmen ovino congelado, fornecem resultados superiores aos diluído em Glicina-Gema-Leite 20\% (GGL20\%).

Segundo Gil et al., (2003), com base em estudos de concentrações de $5,10,15$ e $20 \%$ de gema de ovo em meio à base de leite, nenhum efeito benéfico foi obtido pela utilização de gema de ovo em quantidades acima de $10 \%$ em sêmen ovino refrigerado. Já Roca et al. (1997), observaram que os espermatozóides caprinos foram preservados a $5^{\circ} \mathrm{C}$, durante 6 a 36 horas, em diluidor contendo $2 \%$ de gema de ovo.

Ritar e Salamon (1982) observaram que a concentração de 1,5\% de gema de ovo não interferiu na viabilidade dos espermatozóides caprinos não lavados e coletados fora da estação reprodutiva. 


\section{Metabólitos reativos do oxigênio - ROS}

Metabólitos reativos do oxigênio (ROS, do termo em inglês: reactive oxygen species), radicais livres e oxidantes são termos usados, para identificar os intermediários químicos reativos do metabolismo do oxigênio (HALLIWELL \& GUTTERIDGE, 1999; NORDBERG \& ARNÉR, 2001; apud MAIA, 2006).

O termo radical livre não é considerado o mais adequado, pois nem todos os metabólitos reativos do oxigênio são radicais livres. $O$ mesmo se aplica ao termo oxidante, uma vez que algumas ROS (ex. O2- e H2O2) podem atuar tanto como agentes oxidantes como redutores, em sistemas diferentes. Já o termo, metabólitos reativos do oxigênio (ROS) inclui todos os radicais e não radicais derivados do oxigênio (HALLIWELL \& GUTTERIDGE, 1999).

Os ROS são encontrados em todos os sistemas biológicos. Em condições fisiológicas do metabolismo celular aeróbio, o 02 sofre redução tetravalente, com aceitação de quatro elétrons, resultando na formação de H2O (FERREIRA \& MATSUBARA, 1997; NORDBERG \& ARNÉR, 2001 apud MAIA et al., 2009).

Durante esse processo são formados intermediários reativos como: os radicais superóxido (O2-), hidroperoxila ( $\left.\mathrm{HO}^{-}-\right)$e hidroxila $(\mathrm{OH}-)$ e, o não radical, peróxido de hidrogênio (H2O2). Normalmente, a redução completa do O2 ocorre na mitocôndria e a reatividade dos ROS é neutralizada pela entrada de quatro elétrons (FERREIRA \& MATSUBARA, 1997; NORDBERG \& ARNÉR, 2001).

O radical ânion superóxido (O2-) é um radical livre formado a partir do oxigênio molecular pela adição de um elétron. Sua formação ocorre espontaneamente, especialmente na membrana mitocondrial através da cadeia respiratória. É também produzido por flavoenzimas, lipoxigenases e cicloxigenases (NORDBERG \& ARNÉR, 2001). Sua formação ocorre em quase todas as células aeróbicas e é produzido durante a ativação máxima de neutrófilos, monócitos e eosinófilos (FERREIRA \& MATSUBARA, 1997). Este é um radical pouco reativo e não tem a habilidade de penetrar membranas 
lipídicas, agindo, portanto, apenas no compartimento onde é produzido (NORDBERG \& ARNÉR, 2001).

O peróxido de hidrogênio ( $\mathrm{H} 2 \mathrm{O} 2$ ) não é um radical livre, mas um metabólito do oxigênio extremamente deletério porque participa como intermediário na reação que produz $\mathrm{OH}-$; possui vida longa e é capaz de atravessar membranas biológicas (FERREIRA \& MATSUBARA, 1997; NORDBERG \& ARNÉR, 2001). Uma vez produzido, o H2O2 é removido por um dos três sistemas de enzimas antioxidantes: catalase, glutationa peroxidase e peroxiredutases (NORDBERG \& ARNÉR, 2001).

$O$ radical hidroxila $(\mathrm{OH}-)$ é considerado o radical livre mais reativo em sistemas biológicos, sendo capaz de causar mais danos do que qualquer outra ROS. É formado a partir do peróxido de hidrogênio em uma reação catalisada por íons metais ( $\mathrm{Fe}++$ ou $\mathrm{Cu}+$ ), denominada reação de Fenton (MAIA, 2006).

$O$ radical hidroxila também pode iniciar a oxidação dos ácidos graxos poliinsaturados das membranas celulares, conhecida como lipoperoxidação. Induzem danos ao DNA, a rápida perda do potencial fertilizante dos espermatozóides e perda da adenosina trifosfato do axonema da cauda (FERREIRA \& MATSUBARA, 1997).

A geração de altas concentrações de ROS no sêmen está associada ao declínio no metabolismo de energia do espermatozóide, na motilidade e na viabilidade espermática e com a fragmentação do DNA em cavalos, touros, carneiros, bodes e homens (ARMSTRONG et al., 1999; DURU et al., 2000, apud MAIA, 2006; KRZYZOSIAK et al., 2000; BAUMBER et al., 2002; BILODEAU et al., 2002).

Uma das principais causas da deterioração espermática é o estresse oxidativo (BATELLIER et al., 2001). De fato, as células espermáticas são caracterizadas por sua capacidade incomum de gerar metabólitos oxigênioreativo (ROS), que causam peroxidação lipídica, especialmente durante a sobrevivência espermática (SALAMON \& MAXWELL, 2000; BATELLIER et al., 2001). 


\subsection{Mecanismo de ação dos antioxidantes}

Antioxidante pode ser definido como qualquer substância que, quando presente em baixas concentrações comparadas aquela do substrato oxidável, retarda ou previne significativamente, a oxidação daquele substrato. A adição de antioxidantes ao diluente tem sido avaliada quanto à sua capacidade de proteger o espermatozóide do efeito tóxico dos ROS, (HALLIWELL \& GUTTERIDGE, 1999; apud MAIA 2006).

Os níveis de antioxidantes presentes normalmente no sêmen ainda são parcialmente removidos com a diluição do sêmen o que pode reduzir consideravelmente o efeito benéfico do antioxidante natural, assim, a adição destes agentes, mesmo em pequenas concentrações, pode melhorar a função espermática do sêmen manipulado (MAIA, 2006).

Para proteger do efeito letal da formação excessiva de ROS, a célula possui um sistema de defesa antioxidante enzimático e um não enzimático (NORDBERG \& ARNER, 2001), a saber:

- Enzimático: neutralizam o excesso da formação das ROS e previnem os danos a estruturas celulares. São compostos pelas enzimas: Superoxido dismutase (SOD); Catalase (CAT), peroxiredoxinas (Prx), Glutationa $(\mathrm{GSH})$, glutationa redutase (GR), e glutationa peroxidase (GPX) (NORDBERG \& ARNER, 2001).

- Não enzimático: compostos de baixo peso molecular, incluindo as vitaminas $C$ e $E$, diferentes compostos de Selênio, ubiquinonas (coenzima Q), Ácido Úrico e Ácido lipoíco (NORDBERG \& ARNER, 2001).

Esse sistema pode atuar em duas linhas: como removedor do agente antes que ele cause lesão (glutationa reduzida, superoxido dismutase, catalase, glutationa peroxidase e vitamina E) ou como reparador da lesão ocorrida (ácido ascórbico, GR e GPX) (FERREIRA \& MATSUBARA, 1997).

Com exceção da vitamina $E$, que é um antioxidante estrutural da membrana, a maior parte dos agentes antioxidantes encontram-se no meio intracelular (FERREIRA \& MATSUBARA, 1997). 


\subsection{Antioxidantes}

\subsubsection{Trolox $®$}

O 6-hidroxi-2,5,7,8-tetrametil croman-2-ácido carboxílico, nomeado de Trolox®, é um análogo hidrossolúvel do tocoferol que foi sintetizada por Scott e sua equipe em 1974. Esta substância apresenta propriedades antioxidante maiores que a das (Vitamina E) a e $\mathrm{Y}$-tocoferol, tanto em gordura animal quanto vegetal (CORT et al., 1975).

O mecanismo de ação do efeito antioxidante do Trolox® é semelhante ao da vitamina $\mathrm{E}$, ou seja, envolve $\mathrm{O} \mathrm{OH}$ - fenólico e a remoção de radicais peroxil (ALBERTINI \& ABUJA, 1999). Sua estrutura é composta por um núcleo "croman", semelhante ao do a- tocoferol, e um grupo ácido carboxílico no carbono 2 (REZK et al., 2004).

A maioria das ROS, por exemplo, o ânion superóxido é gerado em fase aquosa, assim o Trolox $(\mathbb{R}$ apresenta vantagem sobre os outros antioxidantes que são apenas lipossolúveis, como a vitamina E. (FERREIRA \& MATSUBARA, 1997; NORDBERG \& ARNÉR, 2001; apud MAIA et al.,2009).

Devido a sua estrutura cromonal, que lhe dá atividade antioxidante e ao grupo carboxila, que tem moderado efeito hidrossolúvel, o Troloxß é distribuído em ambas às fases da bicamada de lipídios das biomembranas, tornando-se um excelente protetor contra a lipoperoxidação (BARCLAY et al., 1995 apud MAIA, 2006).

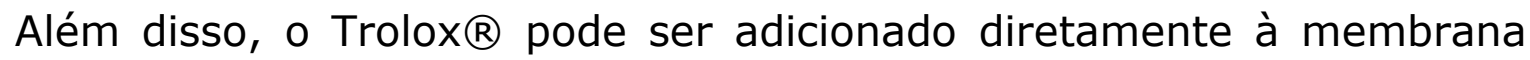
lipídica (membrana intacta) sem a necessidade de solventes ou outros métodos de extração (BARCLAY et al., 1995 apud MAIA, 2006).

\subsubsection{Catalase}

A catalase é uma heme-proteína citoplasmática, e se localiza nos peroxissomos das células de mamíferos, atuando como antioxidante enzimático e catalisa a redução do peróxido de hidrogênio (H2O2) à água (H2O) e oxigênio molecular (O2). Também atua na destoxificação de diferentes 
substratos (ex. fenóis e alcoóis), via redução do peróxido de hidrogênio (MAIA, 2006).

A função da catalase como antioxidante é diminuir o risco de formação do radical hidroxila ( $\mathrm{OH}-$ ) a partir do $\mathrm{H} 2 \mathrm{O} 2$ via reação de Fenton (FERREIRA \& MATSUBARA, 1997) e também tem um papel importante no controle do estresse oxidativo da célula espermática, possivelmente resultante da presença da H2O2 (BUCAK et al, 2007).

A catalase atua apenas nas porções aquosas das células, portanto partes lipídicas como a membrana celular permanecem desprotegidas e susceptíveis a ação de peróxidos de hidrogênio (FERREIRA \& MATSUBARA, 2006). E também exerce a função de remoção do O2- gerado pela NAPDH oxidase dos neutrófilos e desempenham papel importante na diminuição da lipoperoxidação (LPO) e protegem os espermatozóides dos danos oxidativo (SIKKA, 1996).

\section{Refrigeração de sêmen caprino}

Na conservação das células espermáticas de caprinos são utilizadas duas técnicas básicas: a congelação e a refrigeração (NUNES, 2001). Na primeira técnica mantém-se o sêmen à temperatura do nitrogênio liquido $\left(-196^{\circ} \mathrm{C}\right)$, por tempo indeterminado, intensificando o uso dos reprodutores.

Na segunda técnica, o sêmen caprino é conservado sob refrigeração em temperaturas entre $15^{\circ} \mathrm{C}$ a $2^{\circ} \mathrm{C}$, porém, as temperaturas mais utilizadas são entre $5^{\circ} \mathrm{C}$ e $4^{\circ} \mathrm{C}$ (ROCA et al. 1997), pois, nos espermatozóides armazenados a $5^{\circ} \mathrm{C}$, as necessidades metabólicas decrescem a aproximadamente $10 \%$ daquela que teriam se estivessem à temperatura de $37^{\circ} \mathrm{C}$ (LEBOUEF et al. 2000).

Segundo Evans \& Maxwell (1987), o período máximo de conservação do sêmen a $5^{\circ} \mathrm{C}$ para obtenção de um grau aceitável de fertilidade através da inseminação artificial é de 24 horas para ovinos e de 48 horas para caprinos. 
Segundo Medeiros et al. (1994) e Gonsalves et al. (2001) o sêmen caprino conservado sob refrigeração a $4^{\circ} \mathrm{C}$ pode ser utilizado em um curto espaço de tempo, tendo uma viabilidade máxima de 48 horas.

No entanto Shamsuddin et al. (2000) e Palomino et al. (2007) concluíram que a viabilidade do sêmen refrigerado a $5^{\circ} \mathrm{C}$ pode chegar até 96 horas e que a motilidade do sêmen se manteve acima de $50 \%$ pós refrigeração dependendo do diluente.

Após a diluição do sêmen caprino, o ritmo de queda de temperatura deve ser compreendido entre $0,25^{\circ} \mathrm{C} / \mathrm{min}$. a $0,35^{\circ} \mathrm{C} / \mathrm{min}$. até atingir a temperatura de $5^{\circ} \mathrm{C}$, mantendo a motilidade dos espermatozóides em baixos níveis por alguns dias (MACHADO e SIMPLÍCIO, 1995).

Douglas-Hamilton et al. (1984), comparando taxas de resfriamento rápido (maiores que $1^{\circ} \mathrm{C} / \mathrm{min}$.), médio (entre $1^{\circ} \mathrm{C} / \mathrm{min}$. e $0,33^{\circ} \mathrm{C} / \mathrm{min}$.) e lento (menores que $0,33^{\circ} \mathrm{C} / \mathrm{min}$.), concluíram que as taxas lenta e rápida causam maiores danos a célula espermática (maior número de patologias, menor motilidade e maior número de células mortas após resfriação) que a taxa média.

\section{Alterações do sêmen durante as curvas de refrigeração}

A membrana celular é composta por proteínas e lipídios. Os lipídios estão organizados de forma bilaminar, onde a porção hidrofílica está direcionada para o exterior e a hidrofóbica está voltada para a face interna da membrana. Essa disposição confere à célula uma barreira hidrofóbica, pela qual a água e as moléculas nela dissolvidas são impedidas de transpor a membrana plasmática. As proteínas permitem a formação de canais hidrofílicos intercalados à barreira hidrofóbica, pois são nesses locais que a água e as moléculas que nela estão dissolvidas conseguem transpor a membrana e, assim, proporcionar trocas entre os meios interno e externo da célula (AMANN \& GRAHAM, 1993). 
O conhecimento obtido sobre as membranas plasmáticas está baseado no modelo do mosaico fluído proposto por Singer e Nicholson (1972), no qual os lipídios estão livres, com movimento lateral, proporcionando fluidez à membrana.

Em temperaturas de $37^{\circ} \mathrm{C}$, os lipídios encontram-se em estado fluído e dispostos de forma aleatória. Quando há diminuição da temperatura do meio em que essas células estão contidas, ocorre um alongamento das cadeias de ácidos graxos, resultando no aumento da sua rigidez. Ocorre então que os fosfolipídios semelhantes tendem a se agrupar, dando origem a estruturas cristalinas de forma hexagonal, e somente uma porção pequena destes fosfolipídios mantém-se na forma líquida. Esse arranjo irá favorecer o deslocamento das proteínas para esses locais, as quais se fundem e, consequentemente, formam agregados proteicos que resultam em aumento da permeabilidade da membrana e na diminuição do metabolismo celular (AMANN \& PICKETT, 1987; STRYER, 1988; AMANN \& GRAHAM, 1993).

Os danos sofridos pelas células espermáticas são irreversíveis, sendo caracterizados por movimento anormal, ou seja, ocorre comprometimento do padrão de motilidade progressiva, assim como sua perda, danos ao acrossomo e à membrana plasmática; aumento da permeabilidade celular; redução do metabolismo; e perda dos componentes intracelulares (GRAHAM, 1996).

Os danos aos espermatozóides podem ser classificados de duas formas: a injúrias diretas do resfriamento e as injúrias indiretas ou latentes (VERNER et al.1988).

As injúrias diretas resultam em alterações da membrana plasmática e subseqüentes danos bioquímicos e metabólicos, que são imediatamente evidenciados pelas alterações de motilidade do espermatozóide ou por meio de testes bioquímicos. Os danos latentes são aqueles detectados somente horas ou dias após as células serem submetidas ao processo de refrigeração e armazenamento entre $0^{\circ} \mathrm{C}$ e $5^{\circ} \mathrm{C}$ (VERNER et al., 1988).

Bispo (2005) relatou que no sêmen caprino a utilização de diluentes a base de gema de ovo foram mais eficazes durante as curvas de refrigeração 
de $-0,33^{\circ} \mathrm{C}$ e $-0,5^{\circ} \mathrm{C}$ até $5^{\circ} \mathrm{C}$ por 24 e 48 horas e na utilização de diluentes a base de leite desnatado somente nas curvas de refrigeração de $-0,5^{\circ} \mathrm{C}$.

\subsection{Equitainer ${ }^{\circledR}$}

Visando o armazenamento e transporte do sêmen em condições adequadas para permanecer com a viabilidade fertilizante, o sistema utilizado Equitainer ${ }^{\circledR}$ foi o primeiro sistema de transporte de sêmen desenvolvido comercialmente (SOUSA, 2002).

Tratando-se de um equipamento durável e reutilizável, sua desvantagem consiste no alto custo de aquisição e necessidade de trocas anuais de componentes. Porém é um sistema estável independente da temperatura ambiente que seja submetido, não alterando as curvas de refrigeração (KATILA, 1997; BRINSKO et al., 2000 apud SOUSA, 2002).

O sistema Equitainer ${ }^{\circledR}$ possui uma taxa de refrigeração inicial de aproximadamente $-0,3^{\circ} \mathrm{C}$ por minuto (KATILA, 1997 apud SOUSA, 2002).

Contudo, por ser um sistema passivo de refrigeração, fornece taxas variáveis de refrigeração, que se reduzem com a diminuição da temperatura interna do sistema (BRINSKO et al., 2000).

Katila (1997) relatou que o Equitainer ${ }^{\circledR}$ é capaz de manter sua temperatura interna de aproximadamente $5^{\circ} \mathrm{C}$ durante até 48 horas, por isto sendo recomendado para períodos de transporte superiores a 24 horas.

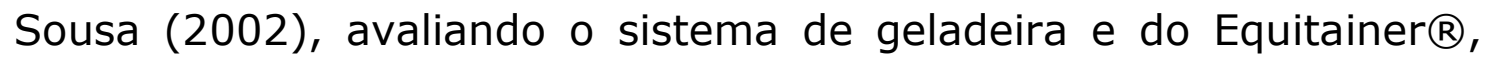
comprovou que a utilização do sistema Equitainer ${ }^{\circledR}$ para refrigeração do sêmen ovino a $5^{\circ} \mathrm{C}$ é viável, por ser um sistema passivo de refrigeração, não sofrendo influencia das oscilações da rede elétrica, da temperatura ambiente, além de apresentar praticidade ao transporte.

\section{Considerações finais}

Aliada a outras biotécnicas reprodutivas, a inseminação artificial representa importante opção como agente de otimização de diferentes 
sistemas de produção de caprinos, contribuindo para uma melhor distribuição dos partos ao longo do ano, diminuindo ou até mesmo suprimindo a entressafra de leite, carne e animais reprodutores, abrandando entraves econômicos e estratégicos para o setor.

A associação entre as ciências da reprodução, sanidade e produção animal objetivam a otimização dos diversos processos desta última área de conhecimento que necessita ser eficiente, onde decisões estratégicas do uso de qualquer técnica de manejo deverão avaliar o seu impacto sobre a produção do ponto de vista biológico e financeiro (DESCHAMPS et al., 2000).

Desta forma, contínuas investigações científicas e esperadas inovações biotecnológicas e sociais para o agronegócio caprinocultura são importantes instrumentos de desenvolvimento regional sustentável.

\section{Referências Bibliográficas}

AAMDAL, J.; LYNGSET, O.; FOSSUM, K. Toxic effect of lysolecithin on sperm a preliminary report. Nordisk Veterinariaer Medicin, v. 17, p. 633- 634, 1965.

ALBERTINI, R.; ABUJA, P.M. Prooxidant and antioxidant proprieties of Trolox C, analogue of vitamin $E$, in oxidation of low-density lipoprotein. Free Radical Research, v.30, n.3, p. 181$188,1999$.

AMANN, R. P.; PICKETT, B. W. Principle of crypreservation and a review of cryopreservation of stallion spermatozoa. J. Equine Vet. Sci., v. 7, p. 147,1987.

AMANN, R. P.; GRAHAM, J. K. Spermatozoa function. In: McKINNON, A. O.; VOSS, J. L. (Ed.) Equine reproduction. Philadelphia: Lea \& Febiger, p. 715- 745, 1993.

ARMSTRONG, J.S.; RAJASEKARAN, M.; CHAMULITRAT, W.; GATTI, P.; HELLSTROM, W.J.; SIKKA, S.C. Characterization of reactive oxygen species induced effects on human spermatozoa movement and energy metabolism. Free Radical Biology \& Medicine, v.26, n.7/8, p. 869-880, 1999.

AZERÊDO, G. A.; ESPER, C. R.; RESENDE, K. T. Evaluation of plasma membrane integrity of frozen-thawed goat spermatozoa with or without seminal plasma.Small Ruminant Research, v. 41, p. $257-263,2001$.

BATELLIER, F.; VIDAMENT, M.; FAUQUANT, J.; DUCHAMP, G.; ARNAUD, G.; YVON, J.M.; MAGISTRINI, M. Advances in cooled semen technology. Animal Reproduction Science, Amsterdam, n. 68, p. 181-190, 2001. 
BARCLAY, L.R.C.; ARTZ, J.D.; MOWAT, J.J. Partitioning and antioxidant action of the watersoluble antioxidant, Trolox, between the aqueous and lipid phases of phosphatidylcholine membranes: $14 \mathrm{C}$ tracer and product studies. Biochimica et Biophysica Acta, v.1237, p.7785, 1995.

BAUMBER, J.; VO, A.; SABEUR, K; BALL, B.A. Generation of reactive oxygen species by equine neutrophils and their effect on motility of equine spermatozoa. Theriogenology, $v$. 57, p.1025-1033, 2002.

BILODEAU, J.F.; BLANCHETTE, S.; CORMIER, N.; SIRAD, M-A. Reactive oxygen speciesmediated loss of bovine sperm motility in egg yolk Tris extender: protection by pyruvate, metal chelators and bovine liver or oviductal fluid catalase. Theriogenology, v.57, p.1105$1122,2002$.

BISPO, C.A.S. - Avaliação "in vitro" do sêmen caprino resfriado a $5^{\circ} \mathrm{C}$ em função de curvas de resfriamento e diluidores. Viçosa-MG, 2005, 79p. Dissertação (Mestrado em Zootecnia) - Universidade Federal de Viçosa - UFV.

BRINSKO, S. P., ROWAN, K. R., VARNER, D. D., BLANCHARD, T. L. Effects of transport container and ambient storage temperature on motion characteristics of equine spermatozoa. Theriogenology, v. 53, p. 1641-55, 2000.

BUCAK, M.N.; SARIOZKAN,S.; TUNCER,P.B.; ULUTAS,P.A.; AKÇADAG,H.I. Effect of antioxidants on microscopic semen parameters lipid peroxidation and antioxidant activies in Angora goat semen following cryopreservation. Small Ruminat Research, 2009. 81, 90-95.

CASTELO,T.S.;FROTA,T.R.;SILVA.A.R. Considerações sobre criopreservação do sêmen de caprinos. Acta Veterinaria Brasilica, v.2, n.3, p.67-75, 2008.

CORT, W.M.; SCOTT, J.W.; ARAUJO, M.; MERGENS, W.J.; CANNALONGA, M.A.; OSCADA, M.; HARLEY, H. PARRISH, D.R.; POOL, W.R. Antioxidant activity and stability of 6-hydroxy-2,5,7,8tetramethylchroman-2-carboxylic acid. Journal of the American Oil Chemist's Society, v.52, n.6, p.174-178, 1975.

CORTEEL, J.M. L'Insémination artificielle caprine: bases physiologiques, état actuel et perspectives d'avenir. World Rev. Anim. Prod., v.9, p.73-99, 1973.

CORTEEL, J.M. Viabilité des spermatozoides de boue conservés et congelés avec ou sans leur plasma seminal effect du glucose. Annales de Biologie Animale, Biochimie, Biophysique, v. 14, n. 1B,p. 741-745, 1974.

CORTEEL, J.M. Production, storage and artificial insemination of goat semen. Management of reproduction in sheep and goats symposium, Madison, v. 24, n. 25, p. 188-274, 1977.

CORTEEL. J.M.; PAQUINON, M. Preservation of the male gamete (ram, buck, boar). In: 10TH INTERNATIONAL CONGRESS ANIMAL REPRODUCTION AND INSEMINATION ARTIFICIAL, 1984, Illinois. Proc... Illinois: 1984, p. 20-27.

DAS, K. K.; RAJKONWAR, C. K. Effects of equilibration periods on the motility of frozen buck semen in raffinose egg yolk glycerol extender. Indian Journal of Animal Research, Haryana, v.29, n.2, p.141-144, 1995. 
DESCHAMPS, J. C.; LUCIA JR., T.; CORRÊA, M. N.; MACEDO, M. C.; RHEINGANTZ, M. G. T. Otimização da eficiência do processo de produção animal a partir do uso de biotécnicas reprodutivas. Rev. Bras. Reprod. Anim., v.24, n.1, p.21-29, 2000.

DOUGLAS-HAMILTON, D. H.; OSOL, R.; OSOL, G. et al. A field study of the fertility transported equine semen. Theriogenology, v. 22, n. 3, p. 291-304, 1984.

DUNNER, S.; IMPASTATO, M.; Effects of amine organic buffers for semen dilution on fertility of does. Small Ruminant Research. 1993. 11, 57-64.

EVANS, G.; MAXWELL, W. M. C. Salamon's artificial insemination of sheep and goats. Butterworth, London, 1987, 194p.

FARSTARD, W. Semen cryopreservation in dogs and foxes. Animal Reproduction Science. $v$. 42, p. 251-260, 1996.

FERREIRA, A.L.A. e MATSUBARA, L.S. Radicais livres: conceitos, doenças relacionadas, sistema de defesa e estresse oxidativo. Rev. Assoc. Méd. Bras. V. 43, n.1, p.1-16, 1997.

GIBBONS, A.. Inseminacion artificial con semen congelado en cabras da raza angora. Revista Taurus, 2002, 4:24-32.

GIL, J.; LUNDEHEIM, N.; SODERQUIST, L.; RODRIGUEZ-MARTÍNEZ, H. Influence of extender, temperature, and addition of glycerol on post-thaw sperm parameters in ram semen. Theriogenology, v. 59, p. 1241-1255,2003.

GONSALVES, P. B. D.; FIGUEIREDO, J. R.; FREITAS, V. J. F. Biotécnica aplicada à reprodução animal. São Paulo: Varela, p. 15-23; 57-65; 111-23, cap. 2, 4 e 7, 2001.

GRAHAM, J. K. Cryopreservation of stallion spermatozoa. Vet. Clin. North. Am., v.12, p.131147, 1996. (Equine Practice).

HALLIWELL, B e GUTTERIDGE, J.M.C. Free Radicals in Biology and Medicine. 3ed., Oxford University Press: New York, 1999. 936p.

HERRERA, J.; TAPIA, A. RESULTADOS EN INSEMINACIÓN ARTIFICIAL EN CABRAS DE RAZA GRANADINA CON SEMEN REFRIGERADO. Producción Ovina y Caprina • 1998 • XXIII: 547549

IRITANI, A.J.; NISHIKAWA, Y. Studies on the egg yolk coagulating factor in goat semen. II. Properties of the coagulating factor and influential condition for coagulation. In: SILVER JUBILEE LAB. ANIM. HUSBANDRY KYOTO UNIVERSITY. 1961, Kyoto. Proc.Kyoto:1961. p.97-104.

KATILA, T. Procedures for handling fresh stallion semen. Theriogenology, v. 48, p. 1217-27, 1997.

KRZYZOSIAK, J. EVENSON, D.; PITT,C.; JOST, L.; MOLAN, P.; VISHWANATH, R. Changes in susceptibility of bovine sperm to in situ DNA denaturation, during prolonged incubation at ambient temperature under conditions of exposure to reactive oxygen species and nuclease inhibitor. Reproduction, Fertility and Development, v.12, p. 251-261, 2000. 
LEBOEUF, B.; RESTALL, B.; SALAMON, S. Production and storage of goat semen for artificial insemination. Animal Reproduction Science, v. 62, p. 113-141, 2000.

LEBOEUF, B.; GUILLOUET, Ph.; BATELLIER, F. et al. Effect of native phosphocaseinate on the in vitro preservation of fresh semen. Theriogenology, v. 60, p. 867-877, 2003.

MACHADO, R.; SIMPLICIO, A. A. Inseminação artificial em caprinos no Brasil: estádio atual. Revista Brasileira Reprodução Animal, v. 19, n. 1-2, p. 61-72, 1995.

MAIA, M.S.; Viabilidade Espermática e Geração de Metabólitos Reativos do Oxigênio (ROS) no Semen Ovino Criopreservado em Diluidor Aditivado de Lauril Sulfato de Sódio (OEP), Trolox-C e Catalase. Botucatu - SP, 2006. Tese (Doutorado em Medicina Veterinária) - Faculdade de Medicina Veterinária e Zootecnia, Campus de Botucatu. Universidade Estadual Paulista "Julio de Mesquita Filho" - UNESP.

MAIA, M.S., BICUDO, S.D., AZEVEDO, H.C., SICHERLE, C.C., SOUSA, D.B., RODELLO, L.. Motility and viability of ram sperm cryopreserved in a Tris-egg yolk extender supplemented with anti-oxidants. Small Ruminant Research. 85, 85-90. 2009.

Medeiros, L. P.; GIRÃO, R. N.; GIRÃO, E. S.; PIMENTEL, J. C. M. Caprinos: Princípios básicos para sua exploração. Teresina: Embrapa-CPAMN/SPI, 1994, p. 63-78.

MIES FILHO, A., DUTRA, J., GIRÃO, R.N. Congelação do sêmen ovino na primavera. Revista Brasileira de Reprodução Animal, v.5, p.27-57, 1982.

MORANI, E.S. Quantificação dos radicais livres produzidos nas diferentes etapas do processo de criopreservação do sêmen de touros. 2004. 79p. Tese (Doutorado), Faculdade de Ciências Agrárias e Veterinárias, Universidade Estadual Paulista-UNESP, Jaboticabal.

NORDBERG, J. e ARNÉR, E.S.J. Reactive oxygen species, antioxidants and the mammalian thioredoxin system. Free Radical Biology \& Medicine, v. 31, n.11, p. 1287-1312, 2001.

NUNES, J. F. Étude des effets du plasma seminal sur la survie in vitro dês espermatozoïdes de bouc. 1982, 45p. Tese (Doutorado em Ciências da Vida) - Université Paris VI, 1982.

NUNES J.F. Inseminação artificial em caprinos. IN: GOLSALVES, P.B.D.; FIGUEIREDO, J.R.; FREITAS, V.J.F. Biotécnias aplicadas à Reprodução Animal. São Paulo: Livraria Varela. p. $111-126,2001$.

PALOMINO, J.M.; CERVANTES, M.; RODRÍGUEZ, A.; CISNEROS, F.; HUANCA, W.; Efecto de dos dilutores y tiempos de refrigeración sobre la motilidad individual de semen refrigerado de caprinos. APPA - ALPA - Cusco, Perú, 2007.

REZK, B. M.; HAENEN, G.R.M.M.; VAN DER VIJGHA, W.J.F.; BAST, A. The extraordinary antioxidant activity of vitamin E phosphate. Biochimica et Biophysica Acta, v. 1683, p. 1621,2004

RITAR, A.J.; SALAMON, S. Effects of seminal plasma and of its removal and of egg yolk in the diluent on the survival of fresh and frozen-thawed spermatozoa of the Angora goat. Aust. J. Biol. Sci., v.35, n.3, p.305-312, 1982. 
ROCA, J.; CARRIZOSA, J.A.; CAMPOS, I. et al. Viability and fertility of unwashed Murcianogranadiana goat spermatozoa diluted in Tris-egg yolk extender and stored at $50 \mathrm{C}$. Small Ruminant Research, v.25, n. 2, p.147- 153, 1997.

RODELLO, L.; BICUDO, S.D.; FALLEIROS, M.B.; MONTEIRO, C.D.; SAKASHITA, S.M. Implicações da redução na concentração de gema de ovo no meio glicina-gema-leite sobre a cinética, morfologia e integridade de membranas espermáticas em sêmen ovino criopreservado. Veterinária e Zootecnia. v.18, n.2 p.239-248, 2011.

SALAMON, S.; MAXWELL, W.M.C. Storage of ram semen. Animal Reproduction Science, Amsterdan, v. 62, p. $77-111,2000$.

SALVADOR, I.; YÁNIZ, J.; VIUDES DE CASTRO, M.P.; GÓMEZ, E.A.; SILVESTRE, M.A.; Effect of solid storage on caprine semen conservation at $5^{\circ} \mathrm{C}$. Theriogenology., v.99, p.974-981, 2006.

SHAMSUDDIN, M.; AMIRI, Y.; BHUIYAN, M.M.U. Characteristics of buck semen with regard to ejaculate numbers, collection intervals, diluents and preservation periods. Reprod. Dom. Anim., v.35, n. 2, p.53-57, 2000.

SIKKA, S.C.; Oxidative stress and role of antioxidants in normal and abnormal sperm function. Frontiers in Bioscience. V.1, p.78-86., 1996.

SIMPLÍCIO, A.A. Inseminação artificial na espécie caprina. Informativo Agropecuário., v. 13, n. 148, p. 30, 1987.

SIMPLÍCIO, A.A.; MACHADO, R. Tecnologia de sêmen e inseminação artificial na espécie caprina. In: CONGRESSO BRASILEIRO DE REPRODUÇÃO ANIMAL, 1989, Belo Horizonte, MG. Anais. BH: CBRA, 1989, p. 171-177.

SINGER, S. J.; NICOLSON, G. L. The fluid mosaic of the structure of cell membranes. Science, n. 175, p. 720-731, 1972.

SOUSA, D.B. Viabilidade do sistema Equitainer ${ }^{\circledR}$ na refrigeração do sêmen ovino avaliado pelas análises computadorizada, de microscopia epifluorescente e inseminação artificial. Botucatu, 2002. Dissertação (Mestrado em Medicina Veterinária), Faculdade de Medicina Veterinária e Zootecnia, Universidade Estadual Paulista "Júlio de Mesquita Filho".

STRYER, L. Biochemistry. In: FREEMAN, W. H. (Ed.) Introduction to biological membranes. 3. ed. New York, 1988. p. 283-310.

TULI, R.K.; HOLTZ, W. Effect of glycerolization procedure and removal of seminal plasma on post-thaw survival and GOT-release from Boer goat spermatozoa. Theriogenology, v. 42, $\mathrm{n}$. 3, p. 547-555, 1994.

VERNER D. D.; BLANCHARD, T. L.; LOVE, C. L. et al. Effects of cooling rates storage temperature on equine spermatozoal motility parameters. Theriogenology, v. 29, n. 5, p. 1043-1054, 1988.

VIANA, A.K.S.; CHALHOUB, M.; RIBEIRO FILHO, A.L.; ALMEIDA, A.K.; PORTELA, A.P.M.; BITTENCOURT, R.F.; ALVES, S.G.G.; BITTENCOURT, T.C.C.; QUINTELA, A.T. Avaliação in vitro do sêmen caprino resfriado, com ou sem centrifugação do plasma seminal e diluído em leite desnatado-glicose e tris-gema de ovo. Ciência Animal Brasileira. v.7, n.1, p.67-76, 2006.

WATSON, P.F. The causes of reduce fertility with cryopreserved semen. Animal Reproduction. Science., v.60-1, p.481-492, 2000. 